unearthed from below level 7, once again Sir Leonard concludes that, throughout, the main influences flowed from the mainland to Cyprus and not vice versa. To this level, too, must be ascribed certain sculptures of Hittite type which were actually found, re-used, in level I. Sir Leonard sees in these the direct forerunners of the lions of early type at Carchemish and of the watergate reliefs of the same city. His argument is further supported by the finding of a bronze lion dagger, almost an exact parallel to the 'dagger god' represented in the Yasilikaya rock carvings. Niqme-Pa's palace has supplied one example of Lower Minoan II pottery, and another contemporary one with the familiar octopus pattern found in a private house. Ivory carvings, which are clearly copies of Egyptian prototypes of the time of Thutmose IV, occur, and contact with Egypt at this time seems to have been close.

The buildings of level 3 are few and poor. The period begins with Suppiluliuma's conquest of North Syria and lasts until 1285 B.c. Throughout this time Alalakh' was ruled by the Anatolian Hittites, which fact explains the difference at this period between it and Ugarit (Ras Shamra), which was only fifty miles away, for the latter did not fall under Hittite control. The influx of Egean settlers and others made of the Syrian coast town an outpost of Late Minoan II civilization, but only a very little Agean influence can be noted at Alalakh.

Level 2 is dated from about 1275 to 1220 B.c. The main interest here is the occurrence of a local Syrian (Mitanni) ware, the decoration of which is ornate with bold rosettes in white on a dark ground and animal and bird forms introduced. A development of this, apparently peculiar to Alalakh, has all-over designs in which the motifs are running water, elaborate stylized lotus plants, and the double axe. The connexion with the Cretan Middle Minoan III is indisputable, though no doubt an example of deferred inspiration.

With the fall of the Hittite power in 1220 B.c., Alalakh was more open to Agean influences. Nearly every grave in Level l contains a Mycenæan vase, and doubtless Ugarit was the connecting link. Then came the great movement of the 'Peoples of the Sea' who swept down, about 1190 B.c., through Anatolia and Syria and were only stopped by Ramses III on the borders of Egypt itself. Ugarit was destroyed, as was Alalakh, and neither site was ever again reoccupied.

To sum up, Sir Leonard Woolley considers that there is evidence for :

(1) "Direct contact with the Asiatic mainland influencing in or before the 18th century the development of the Cretan civilization."

(2) The existence in the Anatolian Hittite confederacy of an important element culturally if not racially akin to the Amorite population of northern Syria.

(3) A possible Asiatic origin of the Cyprus Bronze Age culture.

(4) Egyptian control of northern Syria in the Twelfth Dynasty with, later, a relation between the Hyksos culture and that of the Amk plain.

(5) Direct Late Minoan II and III influences on northern Syria.

(6) The development of Syro-Hittite art in northern Syria long before the beginning of the Syro-Hittite political period and of its kinship with the Hittite art of Anatolia.

\section{ASSOCIATION OF SCIENTIFIC WORKERS}

\section{MEDICAL SCIENCES COMMITTEE}

$\mathrm{A}^{\mathrm{T}}$ $\mathrm{T}$ a conference for workers in the medical sciences arranged by the Association of Scientific Workers, held on January 9 at the London School of Hygiene and Tropical Medicine, Dr. D. McClean (chairman) recalled that the Medica] Sciences Committee of the Association was elected in May, 1942, in an attempt to put into operation the policy of the Association in the medical sciences. That policy was the application of science for the benefit of the community and the raising of the status of the scientific worker. The responsibility for the application of medical science to public needs lies with medical scientists (not medical men alone) themselves ; means should therefore be provided whereby all medical scientists could consult on methods of improving their work and collaborate in the most effective way in pressing for its application in practice.

Mr. Ben Smith, industrial organizer of the Association of Scientific Workers, emphasized the necessity for organization of workers in the medical sciences if they wish to get their policies implemented. Any activity the object of which is to alter existing conditions is necessarily political in nature, and for political activity organization is essential.

Dr. J. H. Humphrey, speaking for the Industrial Health Sub-committee of the Association, said that owing to the increasing numbers of persons working in factories and the extreme specialization in the work, industrial hazards are becoming more complex and important, while the medical personnel available for their prevention and the treatment of their effects are inadequate. Work on industrial hazards was carried out before the War by the Industrial Health Research Board; during the War, the activities of this body have practically ceased, but partly owing to the efforts of the Association it has recently been resuscitated. The Physiological Society has circularized its members to discover whether physiologists are available for full-time or part-time work on industrial health problems. None were available for full-time work, few for part-time. Liaison with shop stewards has also proved very profitable, as workmen themselves have suggested problems for medical research which might otherwise have passed unnoticed. The main difficulty is less to obtain new knowledge than to get what is already well-known applied.

Dr. Yudkin directed attention to the unorganized nature of nutritional research and gave an account of the efforts of the Nutrition Sub-committee of the Association to obtain co-ordination of nutritional research by pressing for the formation of a Nutrition Council.

Dr. C. L. Oakley spoke on the difficulties experienced by research workers in discovering who are working in their own and closely related fields; ignorance of current and unpublished research leads to much duplication of work and waste of time and energy. The specialization of modern research work frequently requires collaboration between experts in various different techniques. Those who wished to collaborate should be encouraged, and for this purpose he suggested the formation of a central bureau at which research work could be registered in title, and from which information could be sent out to 
workers in the same or closely related fields. The most natural body to undertake this work might appear to be the Central Register, since it already possesses the names of all active research workers. Nevertheless, it was pointed out that departmental demarcation within the Civil Service might produce obstacles. He emphasized that the Bureau would exist only for collaboration, not for the staking out of claims in special fields of research. Interested bodies are being circularized to obtain support for this scheme.

Mr. Griffin suggested that the present lack of status of laboratory technicians should be remedied by the introduction of a full course of training for them, followed by a qualifying examination; successful candidates to be enrolled in a State register. To effect this it would be essential to have large numbers of technicians in an organization such as the Association of Scientific Workers, which can undertake trade union activity.

Mr. A. L. Bacharach said that for much biological experimental work animals are as essential as pure chemicals are to the chemist. Of the many thousands of animals of many different species so used, a small percentage only are bred for the purpose; the rest are obtained from dealers. Since the suitability of animals for experimental purposes depends almost entirely on their genetic make-up, their freedom from disease and their diet-subjects on which almost all dealers are lamentably deficient-it is not surprising that a large proportion of dealers' animals are unsatisfactory. Besides this, the demand for animals far exceeds the supply. Adequate supplies of purebred, healthy, well-fed laboratory animals could be obtained only by tackling the problem on a national scale, by the development of Government-controlled breeding centres. A scheme for the development of such centres circulated to learned societies and users has received sufficient support to justify asking the Medical and Agricultural Research Councils and Ministry of Supply to receive a joint deputation of interested parties.

Two resolutions were adopted by the meeting : the first urged the Ministry of Health to secure the compulsory pasteurization of all milk for human consumption, and to take necessary steps to secure the requisite equipment and to reserve adequate skilled personnel; and the second welcomed the setting up of the Allies' Post-War Requirements Bureau, promised full co-operation of the Association on scientific matters, and expressed the hope that the work of the Bureau includes the preparation of relief immediately following Allied intervention on the European continent.

\section{FORTHCOMING EVENTS}

(Meetings marked with an asterisk are open to the public)

Saturday, January 30-Sunday, January 31

Assoclation of SCInNTIFIo WoRk FRs (at Caxton Hall, Westminster, London, S.W.1). Conference on "Planning of Seience in War and in Peace" (to be opened by Sir Robert Watson-Watt, F.R.S.).*

Saturday

At 2.30 p.m. : "The Central Direction of Science".

Sunday

At 10 a.m. : "Local Organisation".

At 2.30 p.m. : "Determining the Future",
Saturday, January 30

SOCIETY OF CHEMTCAL INDUSTRY (in the Chemistry Lecture Theatre of the University of Sheffleld, Western Bank, Sheffield), at 2.30 p.m.Dr. W. H. J. Vernon: "The Corrosion of Metals in Air" (Jubile Temorial Lecture).

\section{Monday, February I}

ROYAL SOCIETY of ARTS (at John Adam Street, Adelphi, London W.C.2), at 1.45 p.m.-Dr. P. Dunsheath: "Industrial Research in Great Britain, a Policy for the Future" (Llewelyn B. Atkinson Memorial Lecture).

Institution of Elibctrioal Engineers (at Savoy Place, Victoria Embankment, London, W.C.2), at 7 p.m.-Prof. C. I. Fortescue : "The Relation between Subsequent Career and the Form of Preliminary Training".

\section{Tuesday, February 2}

INSTITUTION OF CIVIL ENGINHERS (STRUCTURAL AND BUIIDING ENGINGERING DIVISION) (at Great George Street, Westminster London, S.W.1), at 2 p.m. -The Rt. Hon. Viscount Falmouth : "Recent Developments in Fire Research and Fire Protection Problems". 3 p.m.- Sir Lawrence Bragg, F.R.S.: "The Solid State", (ii) "Plusminus Compounds"."

\section{Wednesday, February 3}

ROYAL SoorETy or ARTs (at John Adam Street, Adelphi, London, W.C.2), at 1.45 p.m.-Mr. G. H. Bates: "Agriculture To-day and To-morrow", 4 : "Maintaining the Ploughed-up Area after the War". INSTITUTE OF PAYsIOS (ELEOTRONIOS GRoUP) (in the Lecture
Theatre of the Royal Institution, 21 Albemarle Street, London, W.1), Theatre of the Royal Institution, 21 Albemarle Street, London, W.1), tronic Processes in Solids" (to be opened by Dr. H. Fröhlich).

INSTITUTION OF ELECTRIOAL ENGINEERS (WIRELHESS SROTION) (at Savoy Place, Victoria Embankment, London, W.C.2), at 5.30 p.m.Prof. Willis Jackson: "The University Education" and Industrial Training of Telecommunication Engineers".

INSTTTUTE OF WRLDING (at the Institution of Mechanical Engineers, Storey's Gate, St. James's Park, London, S.W.1), at 6 p.m.-A series of papers on "Developments in Arc Welding Technique".

\section{Thursday, February 4}

Institution of Crvil Engingers (at Great George Street, Westminster, London, S.W.1), at 2.30 p.m. - Fifth (final) Discussion Meeting: "Civil Engineers and the Building Industry-Management and Organization; the Future of the Building Industry" (to be opened by Lord Reith).

\section{Friday, February 5}

ROYAL SOCIETY OF ARTS (INDIA AND BURMA SECTION) (at John Adam Street, Adelphi, London, W.C.2), at 1.45 p.m.-Colonel Sir Malaria in India".

Roxal INSTrTUTion (at 21 Albemarle Street, London, W.1), at 5 p.m.
-Prof. J. C. Drummond: "History and Knowledge of Scurvy and its 'Treatment".

\section{Saturday, February 6}

NUTRITION Societr (at the London School of Hygiene and Tropical Medicine, Keppel Street, London, W.C.1), at 11 a.m.-Conference on "Nutrition in Pregnancy".

BRITISH RHEOLOGISTS' ClUB (at the Royal Society of Arts, John Adam Street Adelphi, London, w.C.2), at 2.15 p.m.-Dr. R. N. Haward: "The Extension and Impact Resistance of some Plastio Materials".

Grorogists' Associntron (at the Geological Soclety, Burlington House, Piccadilly, London, W.1), at 2.30 p.m. - Mr. F. A. Bannister "The Determination of Minerals by X-Ray Methods".

\section{APPOINTMENTS VACANT}

AppLIOATYONS are invited for the following appointments on or before the dates mentioned:

Gas EXaminer (PART-TIME) for tests at Uxbridge and Hampton Court Gas Works--Mr. C. W. Radcliffe, "R.2", Clerk of the County Council, Mjddlesex Guildhall, Westminster, London, S.W.1 (endorsed 'Gas Examiner') (February 3).

IFCrTRT IN hire Technical College, Dudley (February 4).

DIRECTOR OF THE GAS RESEARCH BOARD OF THE GAS INDUSTRYThe Secretary, Gas Research Board, Gas Industry House, 1 Grosveno Place, London, S.W.1 (February 22).

MASTBR mor ENaINERring-The Headmaster, The Gateway School, Leicester.

Imoturer in Evatngeriva (Mechanioar)-The Principal, North Staffordshire Technical College, Victoria Road, Stoke-on-Trent.

Master or MistrRess to TEach PHYsics-The Headmaster, Dover College, Poltimore, Exeter.

LECTURER IN BTOJOGY, MATNLY FOR BOTANY-The Registrar, Municipal College, Portsmouth.

AIR MINISTRY, ASSTSTANT MECHANIOAL AND ELECTRIOAL ENArs for the Provinces-The Ministry of Labour and National Service fortal (Technical and Scientiffic) Register, Section D.315, Sardinia Street, Kingsway, London, W.C.2. 